aprendizaje del euskera un caso que permita extrapolar algunos de los hallazgos sobre las identidades débiles a otros ámbitos? O, por el contrario, ¿no hará la singularidad del caso estudiado que esos hallazgos no puedan ser generalizados, ni siquiera para establecer una teoría de alcance medio? Hay sobradas razones para mantener la especificidad del caso estudiado. La dificultad objetiva de aprender el euskera para los adultos castellano-parlantes en zonas donde habitualmente no se habla ese idioma crea las condiciones de posibilidad para la aparición de esas modalidades débiles de la identidad que viven en un estado de liminalidad permanente. Como el libro recoge, según datos del Gobierno vasco de 1991 , el $56 \%$ de los que han intentado aprender euskera es incapaz de hablarlo. En este sentido, podríamos decir que la elección de Gatti de su objeto de estudio resulta interesada, dado su estatuto privilegiado para toparnos con esas identidades débiles. Nos costará mucho más encontrarlas en otros ámbitos de la vida social, pues en ellos la transición entre identidades fuertes resulta más plausible, dejando así menor espacio social para aquéllas. No obstante, es cierto, como bien argumenta Gatti, que en nuestra sociedad se dan las condiciones sociohistóricas para la aparición de estas modalidades débiles de la identidad, lo cual crea a su vez las condiciones de posibilidad para la elaboración de esa teoría de alcance medio que nos propone. Sin embargo, se echa en falta que el autor no profundice en esta teoría, más allá de mostrarnos cuáles son sus presupuestos. Queda por definir un verdadero programa de investigación que dé lugar a diferentes investigaciones empíricas aplicadas a distintos ámbitos de la vida social. Material y campo para ello hay. En efec- to, la crisis de las instituciones de socialización (trabajo, familia, educación, religión, etc.) está generando, sin duda, nuevas identidades débiles a las que la sociología debe prestar atención. ¿Cómo experimentan su identidad los trabajadores precarios que sueñan con un contrato indefinido pero que ven concatenarse sus contratos temporales, sumiéndoles en una liminalidad permanente? ¿No se encuentran en esta misma situación liminal muchos inmigrantes que iniciaron su proyecto migratorio con la idea de que éste iba a ser transitorio? ¿No se están modificando en algunas clases sociales las llamadas clases de edad, prolongándose con ello el período de transición entre la juventud y la edad adulta, y generando así nuevas posibilidades de crear identidades que parasiten a aquéllas?

José SANTIAGO

Convertirse en anoréxico/a: el trastorno como proceso de desviación

Muriel Darmon

\section{Devenir anorexique. Une approche sociologique}

(Paris, La Découverte, Textes à l'appui, Série Laboratoire des sciences sociales, 2003)

Ya en el título del libro apreciamos el abierto rechazo con que la autora acoge el planteamiento psicopatológico en la etiología del tras- 
torno - como propone la literatura clínica, éste estaría centrado en una determinada estructura de pensamiento: baja autoestima, obsesivos, perfeccionistas, etc. (Garner y Garfinkel, 1982)-. A cambio, nos propone una explicación de lo que podría estar ocultándose tras el padecimiento: la búsqueda de una transformación. Si nadie nace anoréxico, se llega a ser.

Ese cambio sustancial, «ese pasar a ser», en opinión de Darmon, ha de hacer que, como científicos sociales, nos cuestionemos lo considerado normal y lo patológico (Canguilhem, 1986) para constatar cuál es el proceso que define un comportamiento que se desvía de la norma, y analizar así el marco del etiquetado (diagnóstico).

Para la autora, este etiquetado clínico que se realiza en la consulta del profesional psiquiátrico obedece a datos «subjetivos» (como la apariencia física o la interpretación del discurso de los pacientes), pese a que se legitime con los criterios supuestamente neutrales de los manuales de diagnóstico psiquiátricos. Asimismo, ese discurso biomédico permeará al del paciente, que lo integrará buscando la legitimidad del juicio del experto y, a veces, alejándose del sentido inicial que motivó el primer paso en la carrera anoréxica.

Bajo el término «la carrera del anoréxico», la autora nos describe el proceso por el cual determinada parte de la población se conduce hacia la pauta desviada que concluirá con el etiquetado clínico. Pese a que otros autores como Brumberg (1988) hubieran elaborado el trastorno como «carrera», lo novedoso en Darmon es su cuestionamiento del mismo como patología. Brumberg (1988) diferencia dos fases consecutivas: una, que denomina «reclutamiento», que se trataría de una primera etapa de atracción-seducción cultural hacia el modelo estético; y una segunda, que sería la «carrera», en la que se cruza el límite que lleva hacia lo patológico, pero mantiene en todo momento que lo que subyace al trastorno son determinados rasgos de personalidad mórbidos. Pues bien, Darmon va más allá y presenta dicha «carrera» - al estilo de la «carrera moral» de Goffman (1972: 203) — en cuatro pasos, también diferenciados en el tiempo, pero sin dar por hecho que exista una personalidad anoréxica.

El primero de dichos pasos sería lo que determina que el sujeto se disponga a transformarse en función de sus prácticas, un compromiso con el «comportamiento anoréxico». El segundo se referirá a la perduración en el tiempo de dichas prácticas, mediante el desarrollo y planificación del estricto plan de actividades. El tercero plantea la firmeza de dicho compromiso pese a las señales de alerta que señalan el comportamiento como desviado. Por ultimo, el cuarto remite a la toma a cargo del paciente por parte de los profesionales clínicos y las instituciones sanitarias.

La carrera anoréxica aparece como proceso de desviación que comienza siempre por un régimen y al que le sigue la transformación en tres ámbitos: físico, psíquico y social. Los principios que construyen la carrera del anoréxico serían: las disposiciones internas, las externas (instituciones) y la presión social de las interacciones. $Y$ es, justamente, en esa descripción del proceso donde encontramos la parte más innova- 
dora del análisis de los Trastornos de la Conducta Alimentaria: en la contextualización del proceso en su propio tiempo y espacio, poniendo en relación al sujeto con los otros agentes sociales que están presentes en esa carrera (padres, amigos, profesores, clínicos, etc.).

Pese a ser un procedimiento ya clásico en las ciencias sociales - la contextualización de los procesos sociales-, no ha sido la línea de análisis dominante en el estudio de estos padecimientos y es, bajo este abordaje, donde encontramos su aportación más iluminadora, puesto que consigue mostrar las condiciones de posibilidad que permiten que el proceso de conversión (llega a ser anoréxico) sea posible desde el entrecruzamiento de diversas variables (los factores personales, las instituciones y el refuerzo social). Su propuesta busca reconsiderar toda la estructura de los cuidados y la aproximación al trastorno que se practica en la actualidad, cómo confluyen una serie de elementos característicos (en forma de prácticas alimentarias, corporales, escolares, etc.) que originan un contexto de condiciones de posibilidad necesarias - aunque no suficientes - en función de su posición social — género, edad y origen social de las pacientes- que desencadenan el desarrollo del trastorno.

La singularidad de este trabajo en comparación con la vasta bibliografía dedicada al tema es la metodología y técnicas de investigación empleadas: se trata de entrevistas realizadas a chicas adolescentes con el diagnóstico, con sus profesores y con adolescentes de la misma edad, planteando un análisis del padecimiento como objeto de estudio desde la perspectiva de la clínica como proceso de desvia- ción. Su propuesta, sin embargo, adolece de carencias importantes al seleccionar a sus entrevistadas sólo entre las clases medias y altas, pese a que reconozca que se da en otros sectores de la población. En contrapartida, argumenta que es entre éstas donde el trastorno alcanza mayor prevalencia - a tenor de los datos epidemiológicos existentes-, debido a valores propios de dicha posición social como la competitividad y la obsesión por el estatus representado por el cuerpo.

Pese a sus limitaciones, es importante destacar la gran aportación del libro de Darmon al proveernos de una perspectiva de análisis que, hasta el momento, no se había trazado -el padecimiento como proceso de desviación y generación de una subjetividad anoréxica-y que, sin duda, lo convertirá en obra de referencia para todos aquellos/as científicos sociales que se embarquen en la labor de investigar estos trastornos.

\section{Referencias bibliográficas}

BRUMBERG, Joan Jacob (1988): Fasting Girls: The emergence of anorexia nervosa as a modern disease, Cambridge, Harvard University Press.

CANGUILHEM, George (1986): Lo normal y lo patológico, México, Siglo XXI.

GARNER, David Marshall, y GARFINKEL, Paul E. (1982): Anorexia nervosa: a multidimensional perspective, Nueva York, Brunner/Mazel.

GOFFMAN, Erving (1972): Internados: ensayos sobre la situación social de los enfermos mentales, Buenos Aires, Amorrortu.

María Jesús SÁNCHEZ 